\title{
IDENTIFICAÇÃO E CARACTERIZAÇÃO DE ESPÉCIES DE Colletotrichum ASSOCIADAS À ANTRACNOSE DE ANONÁCEAS NO ESTADO DE ALAGOAS ${ }^{1}$
}

\author{
SANDRA HIROMI KAMEI², JAQUELINE FIGUEREDO DE OLIVEIRA COSTA ${ }^{3}$, \\ MARIOTE DOS SANTOS BRITO NETTO ${ }^{4}$, IRAÍLDES PEREIRA ASSUNÇÃO ${ }^{5}$, \\ GAUS SILVESTRE DE ANDRADE LIMA ${ }^{5}$
}

RESUMO- No Brasil, Colletotrichum gloeosporioides é a única espécie associada à antracnose de anonáceas. Contudo, apenas características morfológicas têm sido utilizadas na identificação. Assim, o objetivo do trabalho foi identificar e caracterizar espécies de Colletotrichum que causam a antracnose nas culturas da pinha e da graviola no Estado de Alagoas. Cinquenta e um isolados, obtidos de folhas de pinheira e gravioleira com sintomas típicos da doença, foram coletados em Maceió, Palmeira dos Índios e União dos Palmares. Os isolados foram inoculados em folhas destacadas de ambas as culturas e caracterizados morfologicamente através da morfometria de conídios e apressórios, e molecularmente por meio do sequenciamento da região ITS. Verificou-se que todos os isolados foram patogênicos a ambas as espécies. Na caracterização morfológica, os isolados foram agrupados em três grupos: M1, M2 e M3. O grupo M1 foi formado por 32 isolados com características relacionadas a C. gloeosporioides. No grupo M2, constituído de 15 isolados, predominaram características de $C$. boninense, enquanto, no grupo $\mathrm{M} 3$, composto por quatro isolados, as características foram típicas de $C$. fragariae. A análise filogenética, da mesma forma, também resultou em três grupos (F1, F2 e F3), os quais, de modo geral, estiveram em concordância com os dados da morfologia. $\mathrm{O}$ grupo filogenético F1 concentrou os isolados do grupo morfológico M1 e sequências de referências de C. gloeosporioides e C. fragariae. O grupo $\mathrm{F} 2$, que agrupou as sequências de $C$. boninense, concentrou os isolados do grupo morfológico M2. Finalmente, o grupo F3 incluiu sequências de C. magna e outros quatro isolados desse estudo. Assim, foi possível comprovar que quatro espécies de Colletotrichum são responsáveis pela antracnose em pinheira e gravioleira em Alagoas: $C$. gloeosporioides, $C$. boninense, $C$. fragariae e C. magna.

Termos para indexação: Pinha. Graviola. Região ITS.

\section{IDENTIFICATION AND CARACTERIZATION OF Colletotrichum SPECIES ASSOCIATED WITH ANTHRACNOSE OF ANNONACEOUS CROPS IN THE STATE OF ALAGOAS, BRAZIL}

\begin{abstract}
Anthracnose is an important disease of Annonaceae caused by Colletotrichum species. In Brazil, C. gloeosporioides is the only species associated with annonaceous crops, based only on morphological criteria. In view of this, the objective of this study was to identify and characterize species of Colletotrichum infecting sugar apple and soursop trees in the state of Alagoas, Brazil. Fifty-one isolates obtained from sugar apple and soursop leaves with typical symptoms of the disease were collected in the municipalities of Maceió, Palmeira dos Índios and União dos Palmares. The isolates were inoculated in detached leaves of both crops and they were characterized by conidia and appressoria morphometry and also by sequence analysis of the ITS region. All isolates were pathogenic to both crops. According to the morphological characteristics, the isolates were separated into three distinct groups: M1, M2 and M3. M1 group was made up 32 isolates that were closely-related to $C$. gloeosporioides. M2 group was formed by 15 isolates with characteristics of $C$. boninense, while in the M3 group, with four isolates, the characteristics were typical of $C$. fragariae. The phylogenetic analysis also resulted into three groups (F1, F2 and F3), which in general agreed with the morphological data. The F1 group included the isolates of the morphological M1 group, as well as reference sequences of $C$. gloeosporioides and $C$. fragariae. The F2 group, that clustered reference sequences of $C$. boninense, included the isolates of the morphological M2 group. Finally, F3 group included sequences of C. magna and other four isolates of this study. Thus, it is possible to prove that four Colletotrichum species cause anthracnose on sugar apple and soursop trees in the state of Alagoas: C. gloeosporioides, C. boninense, C.fragariae and C. magna).
\end{abstract}

Index terms: Sugar apple, Soursop, ITS sequence.

\footnotetext{
${ }_{1}^{1}$ (Trabalho 175-13) - Recebido em: 07-08-2013. Aceito para publicação em: 12-12-2013. V Congresso Internacional \& Encontro Brasileiro sobre Annonaceae: do gene à exportação (19 a 23 de Agosto de 2013). Botucatu-SP.

${ }^{2} \mathrm{MsC}$ em Produção Vegetal, Universidade Federal de Alagoas. E-mail: sandrakamei@hotmail.com

${ }^{3}$ Doutoranda do Curso de P.G. em Proteção de Plantas, Universidade Federal de Alagoas. E-mail: jaquelinefigueredo@hotmail.com ${ }^{4}$ Doutorando do Curso de P.G. em Fitopatologia, UFRPE. E-mail: mariote_netto@hotmail.com

${ }^{5}$ Prof. Adjunto IV. Lab. de Fitopatologia, Universidade Federal de Alagoas. E-mail: i_assuncao@hotmail.com, gausandrade@yahoo.com.br
} 


\section{INTRODUÇÃO}

As anonáceas (família Annonaceae) englobam um grupo de frutíferas de importância econômica no Brasil e em várias regiões do mundo, sendo constituído por cerca de 2.500 espécies, distribuídas em 132 gêneros (DONADIO, 1997; KAVATI, 1992). Os gêneros mais importantes são Rollinia e Annona, com destaque maior para este último, que agrupa as principais espécies cultivadas, como a pinha (A. squamosa L.) e a graviola (A. muricata L.). No Nordeste, a Bahia é o principal produtor de anonáceas, seguida de Pernambuco e Alagoas, com plantios irrigados e bom nível tecnológico (DONADIO, 1997). Os frutos são comercializados principalmente para produção de polpas para sucos ou para o consumo in natura. Apesar do aumento da produção registrado nos últimos anos, ainda há um grande espaço a ser explorado nos mercados interno e externo, já que as anonáceas agradam ao paladar do mercado americano, europeu e asiático (KAVATI, 1992).

As culturas da pinha e da graviola no Brasil estão sujeitas a várias doenças, sendo a antracnose aquela que causa os maiores prejuízos (LOPEZ, 2005). A doença afeta folhas, ramos e frutos, em diversas fases do desenvolvimento, ocasionando manchas escuras que podem coalescer e levar à queda de folhas. Além de reduzir a produtividade e desqualificar comercialmente os frutos, provoca ferimentos ou lesões que favorecem a infestação de fungos oportunistas e insetos-praga.O fungo Colletotrichum gloeosporioides é considerado o principal agente etiológico dessa doença, que ocorre tanto em pré quanto em pós-colheita (LOPEZ, 2005). No entanto, nesses relatos, a identificação do patógeno baseou-se em características morfológicas e patogênicas, as quais têm sido consideradas insuficientes para a definição de várias espécies de Colletotrichum (WEIR et al., 2012).

A análise filogenética, baseada em sequências da região ITS do rDNA, tem sido considerada uma abordagem extremamente útil na determinação de espécies Colletotrichum e outros fungos filamentosos (SCHOCH et al., 2012). Contudo, em algumas situações, o sequenciamento de outras regiões genômicas é requerido, especialmente quando se trata de C. gloeosporioides (WEIR et al., 2012). Tais abordagens mudaram a visão de que essa é uma espécie monofilética e que era a única ou a principal causadora de antracnose em várias fruteiras tropicais (NASCIMENTO et al., 2010; TARNOWSKI; PLOETZ, 2010).

Considerando que, até o momento, a identificação de espécies de Colletotrichum que causam antracnose em anonáceaes se baseou unicamente em características morfológicas, o presente trabalho objetivou aprofundar tal identificação, associando características morfológica ao sequenciamento da região ITS do rDNA de diversos isolados de Colletotrichum obtidos de pinheira e gravioleira provenientes do Estado de Alagoas.

\section{MATERIAL E MÉTODOS}

Os experimentos foram conduzidos no Laboratório de Fitopatologia Molecular do Centro de Ciências Agrárias da Universidade Federal de Alagoas (CECA-UFAL), no período de novembro de 2009 a julho de 2011.

A partir de amostras foliares de pinheira e gravioleira apresentando sintomas típicos de antracnose, foram coletados e obtidos, entre os anos de 2009 e 2010, cinquenta e um isolados de Colletotrichum provenientes de áreas produtoras alagoanas, nos municípios de Maceió, Palmeira dos Índios e União dos Palmares (Tabela 1). Culturas monospóricas de cada isolado foram obtidas por meio de diluições seriadas de uma solução de esporos, até $10^{-6}$ conídios $/ \mathrm{mL}$ da concentração inicial. Testes de patogenicidade foram realizados em folhas destacadas, sendo cada isolado inoculado em folhas de pinheira e gravioleira com e sem ferimento, num total de quatro folhas por isolado. O inóculo foi preparado a partir de culturas crescidas em meio BDA com sete dias de idade. A inoculação foi feita através da deposição de quatro gotas de $40 \mu \mathrm{L}$ de suspensão com $10^{5}$ conídios/mL sobre a superfície de folhas com e sem ferimentos (realizados com uma agulha flambada). Nas testemunhas, foi utilizada apenas água destilada autoclavada (ADA). As folhas foram acondicionadas separadamente em caixas plásticas - gerbox - contendo papel de filtro umedecido com ADA, sendo os pecíolos envoltos por um chumaço de algodão embebido em ADA. As folhas foram mantidas em incubadora tipo BOD a $25 \pm 1^{\circ} \mathrm{C}$ e fotoperíodo de 12 horas, durante sete dias.

A caracterização morfológica baseou-se no tamanho e no formato de 50 conídios e 50 apressórios de cada isolado, escolhidos aleatoriamente, que foram visualizados em aumento de 400x. Os esporos caracterizados foram produzidos em meio de aveia, à temperatura de $25 \pm 1{ }^{\circ} \mathrm{C}$ e fotoperíodo de 12 horas, por 10 dias. Para a formação de apressórios, uma gota $(40 \mu \mathrm{L})$ de suspensão de esporos foi depositada sobre uma lâmina de vidro estéril, acondicionada em placa de Petri forrada com papel-filtro estéril, umedecido 
com ADA e vedada com filme de PVC. Após 14 a 24 horas, a germinação foi interrompida com solução de lactofenol com azul de algodão, e os apressórios foram observados. Os formatos de conídios e apressórios foram avaliados de acordo com Cannon et al. (2008). Já as medidas das estruturas foram obtidas através de imagens capturadas por câmera digital acoplada ao microscópio óptico, utilizando o software Motic Images Plus 2.0 (Motic ${ }^{\circledR}$ ).

A extração de DNA foi feita a partir de micélio, sendo os isolados cultivados em frascos erlenmeyer com meio sacarose-extrato de leveduraasparagina, por cinco dias, à temperatura de $25 \pm 1{ }^{\circ} \mathrm{C}$, sem agitação, e fotoperíodo de 12 horas, utilizando-se do protocolo de CTAB. A técnica empregada para a amplificação foi a PCR (Reação em Cadeia da Polimerase). Foram utilizados os oligonucleotídeos universais, IST4 e ITS5. As condições de termociclagem da PCR foram: desnaturação inicial a $95^{\circ} \mathrm{C}$ por $1 \mathrm{~min}$, seguida de 35 ciclos formados por $94^{\circ} \mathrm{C}$ por $1 \mathrm{~min}, 60^{\circ} \mathrm{C}$ por $1 \mathrm{~min}$ e $30 \mathrm{seg}$, para anelamento dos oligonucleotídeos e extensão a $72^{\circ} \mathrm{C}$ por 2 min (CAI et al., 2009).

Os produtos de PCR foram sequenciados nos dois sentidos com os mesmos iniciadores utilizados na amplificação pela Macrogen Inc. (Coreia do Sul). Os alinhamentos múltiplos das sequências foram realizados com o programa Clustal W (THOMPSON et al., 1994). As análises filogenéticas foram realizadas utilizando o programa MEGA 5 (TAMURA et al., 2011) pelo método "NeighborJoining", com valor de "bootstrap" 1.000 .

\section{RESULTADOS E DISCUSSÃO}

Todos os isolados testados mostraram-se patogênicos tanto às folhas de pinheira quanto às de gravioleira. As lesões iniciais, características de antracnose, surgiram entre cinco e nove dias após a inoculação. Observou-se ainda que as inoculações realizadas sobre tecidos com ferimentos anteciparam o surgimento dos sintomas em 24 a 48 horas, em relação às inoculações sobre o tecido íntegro.

Com relação à forma dos conídios, prevaleceu o formato reto, cilíndrico, com ápices arredondados; seguido de reto, com constrição; e por fim, reto, cilíndrico, com ápices arredondados, sendo um mais estreito que o outro. Ressalta-se que todos os isolados apresentaram as três formas de conídios, em proporções distintas. Alguns conídios, após a germinação, emitiram um ou dois tubos germinativos com apressórios, sendo esta característica comumente observada para o gênero Colletotrichum (WEIR et al., 2012). Quanto aos apressórios, a forma globosa ou ovoide foi mais frequente que a irregular.

Com base nas características dos conídios e dos apressórios, os isolados foram agrupados em três grupos: M1, M2 e M3 (Tabela 2). O grupo M1, formado por 32 isolados, apresentou conídios retos, cilíndricos, e com ápices arredondados. Esse tipo de conídio está associado a C. gloeosporioides (CANNON et al., 2008). Nesse grupo, as dimensões médias dos conídios foram de 13,0 x 5,2 $\mu \mathrm{m}$ (Tabela 2), com variações de 10,9-19,1 $\mu \mathrm{m}$ e 4,3-8,8 $\mu \mathrm{m}$, para comprimento e largura, respectivamente. A relação comprimento/largura, também usada na identificação de espécies do gênero, variou de 2,0 a 3,2, sendo a média 2,5. Os apressórios apresentaram-se, em sua maioria, globosos ou ovoides e tiveram média de 8,9 x $6,8 \mu \mathrm{m}$, com variações de 7,1-12,0 $\mu \mathrm{m}$ e 5,7 $10,3 \mu \mathrm{m}$, respectivamente. Esses valores novamente corroboram a descrição de Cannon et al. (2008) para C. gloeosporioides.

O segundo grupo (M2) foi constituído por 15 isolados, que também apresentaram maior frequência de conídios retos, cilíndricos, com ápices arredondados. As médias para o comprimento dos conídios também foram semelhantes, com valor de 13,3 $\mu \mathrm{m}$ (Tabela 2), variando de 12,0 a 14,0 $\mu \mathrm{m}$. No entanto, a largura para este foi maior, com média de $6,1 \mu \mathrm{m}$, e amplitude de 5,4 a $6,8 \mu \mathrm{m}$. Consequentemente, foi constatado um valor menor para a relação comprimento/largura, alcançando média de $2,2 \mu \mathrm{m}$, oscilando de 1,8 a 2,6 $\mu \mathrm{m}$. Outra característica útil na distinção destes isolados foi que alguns conídios apresentaram uma pequena cicatriz ou protuberância na base. Essa protuberância é semelhante à encontrada na descrição de $C$. boninense (MORIWAKI et al., 2003). Tozze Júnior et al. (2009) também verificaram conídios com características semelhantes, associando-os à mesma espécie na cultura do pimentão. Para o apressório, o formato globoso foi o mais comum. Nesse caso, as médias variaram de $8,5 \times 7,1 \mu \mathrm{m}$, oscilando de 7,5 a $9,6 \mu \mathrm{m}$ para o comprimento e de 6,2 a $7,8 \mu \mathrm{m}$ para a largura. Essas observações também estão em consonância com a descrição de $C$. boninense (MORIWAKI et al., 2003; TOZZE JÚNIOR et al., 2009).

Para o terceiro grupo (M3), que apresentou apenas quatro isolados, predominaram conídios retos, cilíndricos, com ápices arredondados, sendo um mais estreito que o outro. Esta característica é determinante para distingui-lo dos demais e semelhante à relatada para C. fragariae (GUNNEL; GUBLER, 1992; MACKENZIE et al., 2008), atualmente denominada $C$. theobromicola (WEIR et al., 2012). As dimensões dos conídios foram de 12,4 
x 5,1 $\mu \mathrm{m}$ (Tabela 2), variando de 12,1-12,8 $\mu \mathrm{m}$ para o comprimento e 4,9-5,1 $\mu \mathrm{m}$ para a largura. A média da relação comprimento/largura foi 2,5, oscilando de 2,4 a 2,7. O formato globoso foi predominante para os apressórios desse grupo, e as dimensões variaram de 7,9 x 6,2 $\mu \mathrm{m}$, com amplitude de 7,4-8,5 $\mu \mathrm{m}$ e 5,9-6,6 $\mu \mathrm{m}$, respectivamente. Estes dados foram similares aos encontradas por Villanueva-Arce et al. (2008) para C. fragariae, isolado de cherimólia, no México.

O sequenciamento dos produtos amplificados com o par de primers universais ITS4 e ITS5 revelou fragmentos em torno de 570 pares de bases (pb). Uma árvore filogenética foi construída a partir das sequências obtidas, e os isolados separaram-se por similaridade genética em três grupos: F1, F2 e F3 (Figura 1). O grupo F1, constituído por 28 isolados (13 de pinheira e 15 de gravioleira), incluiu sequências de referências para $C$. gloeosporioides e C. fragariae (C. theobromicola). Dentre os isolados desse grupo, 23 pertencem ao complexo $C$. gloeosporioides e cinco correspondem a $C$. fragariae. A espécie $C$. gloeosporioides já foi relatada como responsável pela antracnose nas culturas da pinha e da graviola (LOPEZ, 2005; CORREIA et al., 2011). Entretanto, esse é o primeiro relato de $C$. fragariae (C. theobromicola) nessas culturas, sendo esse um patógeno comum do morangueiro (MACKENZIE et al., 2008). Anteriormente, C. fragariae consistia em um subgrupo dentro de C. gloeosporioides. No entanto, o sequenciamento e a análise conjunta de vários genes corroboram que esta espécie é distinta do complexo C. gloeosporioides, o qual abrange atualmente 22 espécies e uma subespécie (WEIR et al., 2012). No caso de anonáceas, Villanueva-Arce et al. (2008) relataram sua ocorrência em frutos de cherimólia no México, atribuindo ao patógeno uma elevada importância. Cabe ressaltar que o grupo F1 englobou a maior parte dos isolados que constituíram o grupo M1 da morfologia, além dos quatro isolados do grupo M3.

O grupo F2 correspondeu ao grupo M2 das análises morfológicas com os mesmos 14 isolados, sendo oito de pinheira e seis de gravioleira. Esses isolados agruparam-se com sequências de referência do complexo C. boninense, o qual tem sido relacionado a manchas foliares em vários hospedeiros de importância econômica (TOZZE JÚNIOR et al., 2009; SILVA-ROJAS; ÁVILA-QUEZADA, 2011). Entretanto, sua ocorrência em anonáceas ainda não havia sido relatada.

$\mathrm{O}$ grupo $\mathrm{F} 3$ foi composto por quatro isolados (dois de pinheira e dois de gravioleira), os quais estão mais proximamente relacionados à espécie C. magna, descrita pela primeira vez infectando curcubitáceas nos Estados Unidos (JENKINS JR.; WINSTEAD, 1964) e que fizeram parte do grupo morfológico M1. Apesar de não existir nenhum relato de C. magna associado a anonáceas no Brasil e no mundo, essa espécie foi relatada por Nascimento et al. (2010), infectando mamoeiro no Nordeste brasileiro. Neste estudo, não foi possível separar C. magna de $C$. gloeosporioides com base nas características morfológicas. Contudo, baseando-se na sequência do rDNA, ficou claro que são duas espécies distintas. Resultados semelhantes foram encontrados por $\mathrm{Du}$ et al. (2005) e Nascimento et al. (2010).

No geral, 28 isolados, o que corresponde a $54,9 \%$ do total, foram geneticamente identificados como C. gloeosporioides, sendo encontrados em todos os municípios amostrados, tanto em folhas de pinheira quanto nas de gravioleira. Os 14 isolados de $C$. boninense representaram $27,45 \%$ do total e ocorreram apenas nos municípios de Palmeira dos Índios e União dos Palmares, sendo nove isolados de pinheira e seis de gravioleira. Apesar de esta espécie ainda não ter sido relatada em anonáceas, a morfologia dos conídios, referindo-se especialmente à pequena cicatriz em sua base e largura, foi muito útel para distingui-la de C. gloeosporioides (MORIWAKI et al., 2003). Cinco isolados, representando 9,8\% do total, foram considerados como pertencentes à espécie C. fragariae, atualmente C. theobromicola. Este patógeno foi encontrado apenas no município de União dos Palmares, em ambas as culturas. Para essa espécie, a morfologia dos conídios e dos apressórios foi útel na identificação, assim como descrito por Gunnel e Gubler (1992) e por Villanueva-Arce et al. (2008). Através da análise filogenética, identificaram-se quatro isolados (dois de pinheira $\mathrm{e}$ dois de gravioleira) como C. magna, obtidos dos três municípios estudados e que corresponderam a 7,8\% do total de isolados.

Até então, C. gloeosporioides era considerado o único agente etiológico da antracnose em pinheira e gravioleira no Brasil (LOPEZ, 2005). Contudo, o presente trabalho revelou que outras três espécies estão associadas à doença no Estado de Alagoas. Dessas espécies, apenas $C$. fragariae ( $C$. theobromicola) já havia sido relatada em anonáceas no México. Por outro lado, não se constatou a presença de outras espécies de Colletotrichum, como C. acutatum e C. orbiculare relatados, respectivamente, sobre as culturas da graviola na Colômbia (ÁLVAREZ et al., 2004) e da cherimólia no México (VILLANUEVA-ARCE et al., 2008).

A demonstração de que várias espécies de Colletotrichum podem ocasionar antracnose em pinheira e gravioleira, indica que as dificuldades 
para o manejo dessas doenças são ainda maiores, uma vez que diferentes espécies respondem de forma distinta ao emprego de fungicidas ou de resistência do hospedeiro, assim como apresentam diferentes capacidades de adaptação às condições edafoclimáticas e diferentes eficiências de disseminação e sobrevivência.

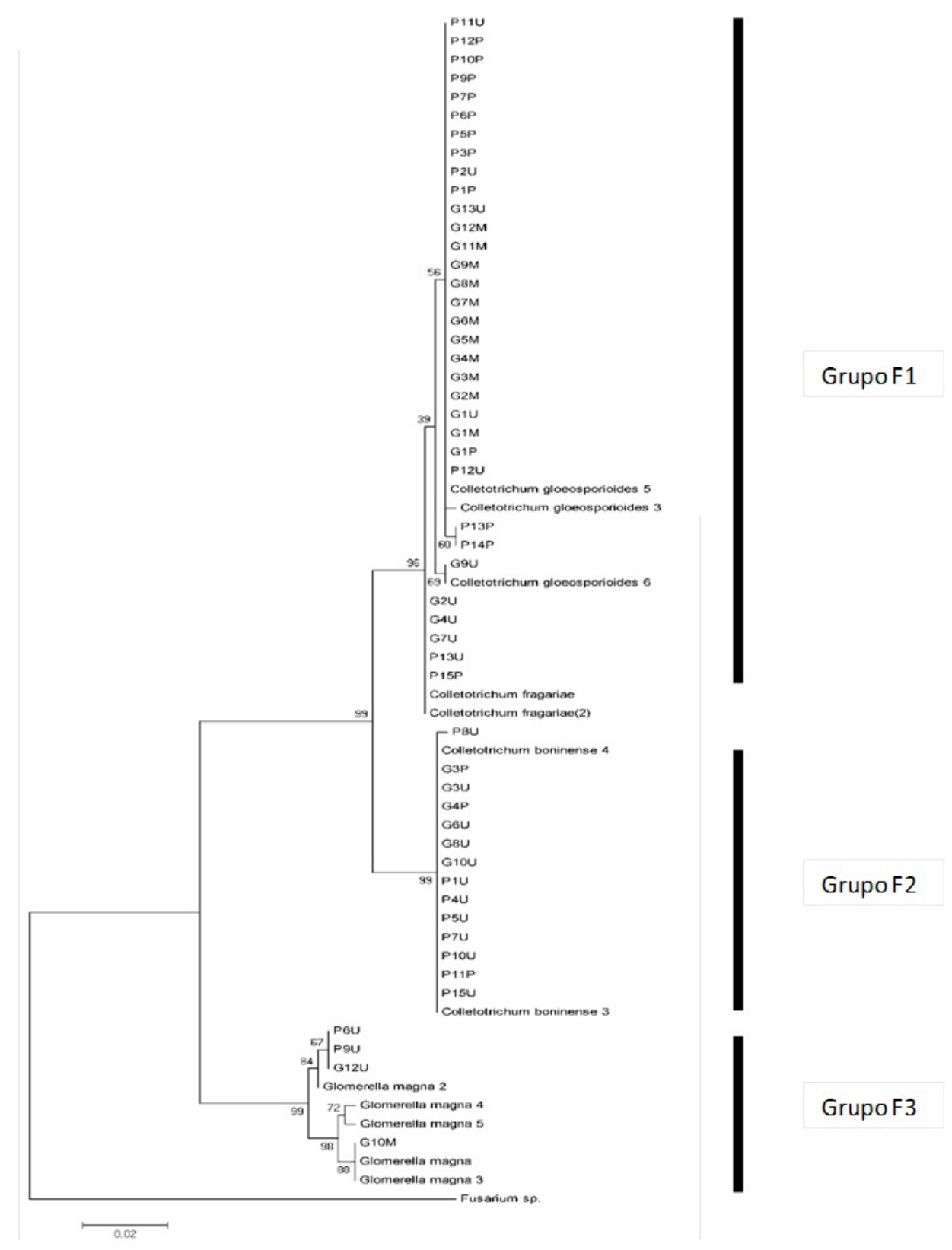

FIGURA 1- Árvore filogenética construída com base nas sequências da região ITS, utilizando o método de "neighbor-joining" com valor de "bootstrap" 1.000 . 
TABELA 1 - Procedência e hospedeiro original de isolados de Colletotrichum obtidos a partir de folhas de pinheira e gravioleira, apresentando sintomas típicos de antracnose.

\begin{tabular}{|c|c|c|}
\hline Isolado & Hospedeiro & Procedência \\
\hline P1U, P2U, P3U, P4U, P5U e P6U & Pinheira & União dos Palmares \\
\hline P7U, P8U, P9U, P10U, P11U, P12U, P13U, P14U e P15U & Pinheira & União dos Palmares \\
\hline $\begin{array}{l}\text { P1P, P3P, P5P, P6P, P7P, P8P, P9P, P10P, P11P, P12P, P13P, P14P } \\
\text { e P15P }\end{array}$ & Pinheira & Palmeira dos Índios \\
\hline $\begin{array}{l}\text { G1M, G2M, G3M, G4M, G5M, G6M, G7M, G8M, G9M, G10M } \\
\text { e G11M }\end{array}$ & Gravioleira & Maceió \\
\hline G1U, G2U, G3U, G4U, G6U, G7U, G8U, G9U e G10U & Gravioleira & União dos Palmares \\
\hline G12U e G13U & Gravioleira & União dos Palmares \\
\hline G1P, G3P e G4P & Gravioleira & Palmeira dos Índios \\
\hline
\end{tabular}

TABELA 2 - Grupos morfológicos, formas e dimensões de conídios e de apressórios dos isolados de Colletrotrichum spp. utilizados neste estudo.

\begin{tabular}{cccc}
\hline \multirow{2}{*}{ Grupo } & Isolados & Conídios & Apressórios \\
\cline { 2 - 4 } & Forma & Média $(\mu \mathrm{m})$ Relação C/L* & Forma \\
\hline
\end{tabular}

P2U, P6U, P9U, P11U, P12U, P1P, P3P, P5P, P6P, P7P, P9P,

P12P, P13P, P14P, P15P, G1M, Retos, cilíndricos,
M1 G2M, G3M, G4M, G5M, com ápices G6M, G7M, G8M, G9M, arredondados G11M, G12M, G1U, G9U, G12U, G13U e G1P

P1U, P4U, P5U, P7U, P8U,

M2 P10U, P15U, P10P, P11P, Retos, cilíndricos,

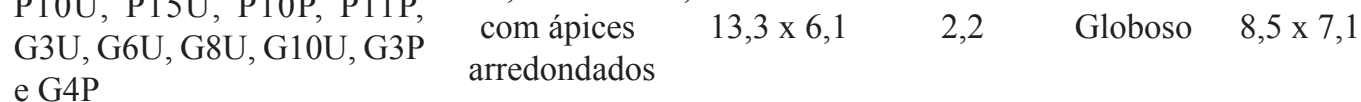

\begin{tabular}{ccccc}
\hline & $\begin{array}{l}\text { Retos, cilíndricos, } \\
\text { com ápices } \\
\text { arredondados, } \\
\text { sendo um mais } \\
\text { estreito que o } \\
\text { outro }\end{array}$ \\
$\quad$
\end{tabular}

*Relação comprimento/largura 


\section{REFERÊNCIAS}

Álvarez, E.; OSPINA, C. A.; MEJÍA, J. F.; LLANO, G. A. Caracterización morfológica, patogénica y genética del agente causal de la antracnosis (Colletotrichum gloeosporioides) em guanábana (Annona muricata) en el Valle del Cauca. Fitopatología Colombiana, Palmira, v. 28, n. 1, p. 1-8, 2004.

CAI, L.; HYDE, K.D.; TAYLOR, P.W.J.; WEIR, B.S.; WALLER, J. A polyphasic approach for studying Colletotrichum. Fungal Diversity, Chiang Mai, v.39, p.183-204, 2009.

CANNON, P. F.; BUDDIE, A. G.; BRIDGE, P. D. The typification of Colletotrichum gloeosporioides. Mycotaxon, Ithaca, v. 104, p. 189-204, 2008.

CORREIA, K. C.; MARTINS, R. B.; CÂMARA, M. P. S.; MICHEREFF, S. J. Escala diagramática para avaliação da severidade da antracnose em pinha. Ciência Rural, Santa Maria, v. 41, n. 1, p. 1-4, 2011.

DONADIO, L. T. Situação atual e perspectiva das anonáceas. In: SÃO JOSÉ, A.R.; SOUZA, I. V. B.; MORAIS, O. M.; REBOUÇAS, T. N. H. Anonáceas: mercado (pinha, graviola, atemoia e cherimólia). Vitória da Conquista: UESB, 1997. p. 7-19

DU, M.; SCHARDL, C. L.; NUCKLES, E. M.; VAILLANCOURT, L. J. Using mating-type gene sequences for improved phylogenetic resolution of Collectotrichum species complexes. Mycologia, Lawrence, v. 97, n. 3, p. 641-658, 2005.

GUNNEL, P. S.; GUBLER, W. D. Taxonomy and morphology of Colletotrichum species pathogenic to strawberry. Mycologia, Lawrence, v. 84, n. 2, p. 157-165, 1992.

JENKINS JR., S. F. J.; WINSTEAD, N. N. Glomerella magna, cause of a new anthracnose of cucurbits. Phytopathology, Saint Paul, v. 54, p. 452-454, 1964.

KAVATI, R. O. Cultivo da atemoia. In: DONALD, L.C. et al. (Ed.). Fruticultura tropical. Jaboticabal: FUNEP, 1992. p. 39-70.
LOPEZ, A. M. Q. Doenças das Anonáceas e do Urucuzeiro. In: KIMATI, H. et al. (Eds.). Manual de fitopatologia. 4. ed. São Paulo: Agronômica Ceres, 2005. v.2, p. 73-77.

MACKENZIE, S. J.; MERTELY, J. C.; SEIJO, T. E.; PERES, N.A. Colletotrichum fragariae is a pathogen on hosts other than strawberry. Plant Disease, Saint Paul, v. 92, n. 10, p. 1.432-1.438, 2008.

MORIWAKI, J.; SATO, T.; TSUKIBOSHI, T. Morphological and molecular characterization of Colletotrichum boninense sp. Nov. from Japan. Mycoscience, Tokyo, v. 44, n. 1, p. 47-53, 2003.

NASCIMENTO, R.J.; MIZUBUTI, E. S. G.; CÂMARA, M. P. S.; FERREIRA, M. F.; MAYMON, M.; FREEMAN, S.; MICHEREFF, S. J. First report of papaya fruit rot caused by Colletotrichum magna in Brasil. Plant Disease, Saint Paul, v. 94, n. 12, p.1506, 2010.

SCHOCH, C.L.; SEIFERT, K.A.; HUHNDORF, S.; ROBERT, V.; LEVESQUE, C.A. WEN, C. Nuclear ribosomal internal transcribed spacer (ITS) region as a universal DNA barcode marker for fungi. Proceedings of the National Academy os Science USA, Washington DC, v. 109, n. 16, p. 6241-6246, 2012 .

SILVA-ROJAS, H. V.; ÁVILA-QUEZADA, G. D. Phylogenetic and morphological identification of Colletotrichum boninense: a novel causal agent of anthracnose in avocado. Plant Pathology, London, v. 60 , n. 5, p. 899-908, 2011.

TAMURA, K.; PETERSON, D.; PETERSON, N.; STECHER, G.; NEI, M.; KUMAR, S. MEGA5: molecular evolutionary genetics analysis using maximum likelihood, evolutionary distance, and maximum parsimony methods. Molecular Biology and Evolution, Oxford, v. 28, n. 10, p. 2731-2739, 2011.

TARNOWSKI, T. L. B.; PLOETZ, R. C. First Report of Colletotrichum boninense, C. capsici, and a Glomerella sp. as causes of postharvest anthracnose of passion fruit in Florida. Plant Disease, Saint Paul, v. 94, n. 6 , p. 86-87, 2010. 
THOMPSON, J. D.; HIGGINS, D. G.; GIBSON, T. J. CLUSTAL W: improving the sensitivity of progressive multiple sequence alignment through sequence weighting, position-specific gap penalties and weight matrix choice. Nucleic Acids Research, Oxford, v. 22, n. 22, p. 4673-4680, 1994.

TOZZE JÚNIOR, H. J.; MASSOLA JÚNIOR, N. S.; CÂMARA, M. P. S.; GIORIA, R.; SUZUKI, O.; BRUNELLI, K. R.; BRAGA, R. S.; KOBORI, R. F. First report of Colletotrichum boninense causing anthracnose on pepper in Brazil. Plant Disease, Saint Paul, v. 93, n. 1, p. 106, 2009.
VILLANUEVA-ARCE, R.; YÁÑEZ-MORALES, M. J.; HERNÁNDEZ-ANGUIANO, A. M. Espécies de Colletotrichum en chirimoya (Annona cheriSmola Mill.). Agrociencia, Chapingo, v.42, n.6, p.689-701, 2008.

WEIR, B. S.; JOHNSTON, P. R.; DAMM, U. Colletotrichum gloeosporioides species complex. Studies in Mycology, Utrecht, v. 73, n. 1, p. 115$180,2012$. 